\title{
Prioridades y medios de la estrategia de comunicación de la Unión Europea: aciertos y desafíos*
}

\author{
Priorities and Means of the European Union's Communication Strategy: \\ Successes and Challenges
}

\author{
Marta Hernández Ruiz \\ Doctora en Estudios Europeos por la Universidad CEU San Pablo \\ Investigadora en el Instituto Universitario de Estudios Europeos de la Universidad CEU San Pablo \\ marta.hernandezruiz@ceu.es
}

doi: http://dx.doi.org/10.18543/ced-59-2018pp141-174

Sumario: I. Introducción.-II. Los objetivos de la estrategia de comunicación de la Unión Europea.-III. La Comisión Europea: estructura organizativa y presupuestos en comunicación. 1. La estrategia de comunicación en las Comisiones Barroso (2004-2014). 2. La estrategia de comunicación en la Comisión Juncker (2014-). 3. Presupuesto de la Dirección General de Comunicación de la Comisión Europea.-IV. El Parlamento Europeo: estructura organizativa y presupuestos en comunicación. 1. Estructura organizativa de la Dirección General de Comunicación del Parlamento Europeo. 2. Presupuesto de la Dirección General de Comunicación del Parlamento Europeo.-V. Conclusiones.-VI. Bibliografía.

Resumen: Desde el rechazo al Tratado Constitucional en los referéndums de Francia y Países Bajos, la Comisión Europea y el Parlamento Europeo han liderado el esfuerzo por mejorar la comunicación entre la Unión Europea y sus ciudadanos. El propósito de este artículo es estudiar sus estrategias comunicativas a partir de tres ejes: los objetivos que las propias instituciones han designado como prioritarios en materia de comunicación, la estructura organizativa que la Comisión Europea y el Parlamento Europeo han elegido para lograr esos propósitos y el presupuesto que han destinado estas instituciones para ello.

Este método de análisis relacional permite estudiar la estrategia de comunicación de la Unión Europea como una estructura. Se parte de la premisa de que los tres ejes deben ser coherentes entre sí para lograr una estrategia eficiente. Y, a partir de las conclusiones alcanzadas, se realizan propuestas de mejora pragmáticas.

Palabras clave: Comunicación; Unión Europea; DG COMM; Comisión Europea; Parlamento Europeo.

* Recibido el 5 de abril de 2018, aceptado el 7 de junio de 2018. 
Abstract: After the rejection of the Constitutional Treaty, as a result of the referendum in France and the Netherlands, the European Commission and the European Parliament have led the strategy to improve communication between the European Union and its citizens. The purpose of this article is to study the EU communication strategy regarding three main aspects: The objectives that the European institutions have designated as priorities in terms of communication, the organizational structure that the European Commission and the European Parliament have chosen to achieve those objectives and the budget that the EU institutions have allocated for their respective Directorate-General for Communication.

This method makes it possible to study the communication strategy as a structure. It is based on the premise that the three main aspects must be coherent with each other in order to achieve an efficient strategy. Finally, pragmatic improvement proposals will be made, according to the conclusions reached in the aforementioned.

Keywords: Communication; European Union; DG COMM; European Commission; European Parliament.

\section{Introducción}

Las instituciones europeas afrontan cada día el reto de comunicarse con la población de manera eficiente. No es un propósito sencillo, teniendo en cuenta la complejidad de la Unión Europea y la dificultad de compararla con el modelo político estatal. Para conseguirlo, la Unión Europea ha ido desarrollando, a lo largo de los años, un profundo debate sobre la estrategia que debe seguir para comunicarse mejor con sus ciudadanos.

Si bien el modelo de comunicación actual tiene sus raíces en los debates previos a la entrada en vigor del Tratado de Maastricht ${ }^{1}$, hubo un punto de inflexión en 2005, tras el rechazo a la Constitución Europea en los referéndums de Francia y Países Bajos. Este fracaso fue difícil de aceptar para las instituciones europeas, y se instó a la Comisión a que liderase un periodo de reflexión para identificar las causas.

La Comisión concluyó que, entre otros factores, había un problema de comunicación con los ciudadanos. Desde entonces, tanto esta institución como el Parlamento Europeo decidieron priorizar sus estrategias destinadas a este fin. Ello puede comprobarse observando los presupuestos que han otorgado a sus Direcciones Generales de Comunicación en los últimos años (entre 72 y 106 millones de euros anuales cada una, como se explicará en posteriores apartados).

${ }^{1}$ Comisión Europea, Libro blanco sobre una política europea de comunicación (Bruselas: 2006), 4, http://www larioja.org/empleo-formacion/es/observatorio-empleo/fondo-socialeuropeo/comunicacion/comunicacion-igualdad-oportunidades .ficheros/617802-493569_ Libro_blanco_politica_europea_comunicacion.pdf 
Por el contrario, las instituciones intergubernamentales suelen realizar una inversión mucho más moderada: el Consejo de la UE dedica a su Dirección General de Comunicación y Gestión de Documentos un presupuesto de, aproximadamente, 10 millones de euros anuales ${ }^{2}$. Por su parte, el Consejo Europeo sólo cuenta con un gabinete integrado en el equipo del presidente y se apoya en la estructura del Consejo.

En coherencia con ello, el propósito de este artículo es estudiar la estrategia comunicativa de la Comisión y el Parlamento Europeo, que lideran a la UE en este ámbito. Este análisis se va a realizar a partir de tres ejes:

- Los objetivos que las propias instituciones han designado como prioritarios en materia de comunicación.

- La estructura organizativa que la Comisión Europea y el Parlamento Europeo han elegido para lograr esos propósitos.

- El presupuesto desglosado que han destinado estas instituciones para ello.

Este método de análisis relacional permite estudiar la estrategia de comunicación de la Unión Europea como una estructura. Se parte de la premisa de que los tres ejes deben ser coherentes entre sí para lograr una estrategia de comunicación eficiente. Y, a partir de ello, se realizarán propuestas de mejora pragmáticas.

Así, en el epígrafe II del presente artículo se identifican los objetivos generales de la estrategia de comunicación de la UE. Acto seguido, en los epígrafes III y IV, se estudian, a partir de los tres ejes mencionados, las estrategias concretas que han seguido respectivamente la Comisión y el Parlamento Europeo. Y, por último, en el apartado de Conclusiones, se realiza un análisis de coherencia entre los objetivos estratégicos identificados y las actuaciones de la Comisión y del Parlamento Europeo.

\section{Los objetivos de la estrategia de comunicación de la Unión Europea}

Según la web explicativa del Parlamento Europeo ${ }^{3}$, las bases de la política de comunicación de la UE están en el artículo 11 de la Carta de Derechos Fundamentales de la UE (derecho a la información y libertad de expresión, además de a la libertad y diversidad de los medios), en el artículo 41 (derecho a ser escuchado y a acceder a documentos relacionados

${ }^{2}$ Consejo de la Unión Europea, 2016 annual activity report of the authorising officer by delegation (Bruselas: Directorate-General Communication and Document Mangement, 2017), 10.

3 «Communication policy», Parlamento Europeo, acceso el 12 de febrero de 2018, http:// www.europarl.europa.eu/atyourservice/en/displayFtu.html?ftuId=FTU_3.6.8.html 
con uno mismo ${ }^{4}$ ), en el artículo 42 (derecho al acceso a los documentos de las instituciones europeas ${ }^{5}$ ) y en el artículo 44 (derecho de petición). También, en determinados casos, en el artículo $352^{6}$ del TFUE ${ }^{7}$.

Como se anticipaba, el rechazo al proyecto de Constitución de 2005 fue especialmente importante por la carga simbólica que tenía, y por el hecho de que el 'no' se hubiese producido en dos países fundadores, como Francia y Países Bajos. Esto obligó a la UE, a través de la Comisión, a reflexionar sobre qué era lo que estaba pasando, y por qué no se había conseguido que la ciudadanía valorase sus logros.

La Comisión publicó diversos documentos sobre lo ocurrido. Entre ellos, podemos citar el Plan D, de otoño de $2005^{8}$ y el Plan de Acción de la Comisión para mejorar la comunicación, publicado en verano de ese mismo año ${ }^{9}$. Meses después, se plasmó el debate que proponían ambos documentos en un Libro Blanco sobre una política europea de comunicación ${ }^{10}$, que veía la luz en febrero de 2006.

Se han identificado, a partir del análisis de dichos documentos (especialmente del Libro Blanco sobre una política europea de comunicación, puesto que aludía a los debates planteados en los anteriores), cuatro objetivos que han determinado las políticas de comunicación desde entonces. Son propósitos que pretenden ser comunes para todas las instituciones europeas, aunque cada una tuviese que desarrollar, teniéndolas en cuenta, una estructura organizativa diferenciada.

En primer lugar, se decidió priorizar la coordinación interinstitucional en comunicación. Se estimó que había que acrecentar la colaboración entre las instituciones europeas, y también implicar a los órganos políticos nacionales, puesto que todos tienen una responsabilidad en el mensaje que se transmite en nombre de la Unión Europea.

${ }^{4}$ Este derecho también puede encontrarse en el art. 15 del TFUE, en el 11.2 del TUE y en Reglamento (CE) n. ${ }^{\circ}$ 1049/2001 del Parlamento Europeo y del Consejo, de 30 de mayo de 2001, relativo al acceso del público a los documentos del Parlamento Europeo, del Consejo y de la Comisión.

${ }^{5}$ El art. 20.2.d) del TFUE también aborda este derecho.

${ }^{6}$ Este artículo «contiene una disposición por la que se autoriza a la Unión Europea (UE) a adoptar un acto necesario para alcanzar los objetivos asignados por los tratados cuando estos no hayan previsto los poderes de acción necesarios para alcanzar dichos objetivos».

7 «Competencias subsidiarias», Eur-lex, acceso el 12 de febrero de 2018, http://eur-lex. europa.eu/summary/glossary/subsidiary_powers.html?locale=es.

${ }^{8}$ Comisión Europea, Plan D: democracia, diálogo y debate (Bruselas: 2005), http://eurlex.europa.eu/legal-content/ES/TXT/?uri=URISERV\%3Aa30000

${ }^{9}$ Comisión Europea, Communication to the Commission. Action plan to improve communicating Europe by the Commission (Bruselas: 2005), http://ec.europa.eu/transparency/ regdoc/rep/2/2005/EN/2-2005-985-EN-F-0.Pdf

${ }^{10}$ Comisión Europea, Libro blanco sobre una política europea de comunicación. 
En segundo lugar, había que conseguir que los medios de masas abordasen más los asuntos comunitarios. La Comisión se quejaba de que la cobertura mediática de la UE era muy incompleta, a pesar de que, en esos años previos a la crisis económica, había más de mil periodistas acreditados en Bruselas. Se hacía, además, un llamamiento a que se facilitasen todos los recursos posibles a los periodistas: tecnología para que hiciesen retransmisiones en directo, contenidos audiovisuales, platós para grabar, notas de prensa, briefings, etc.

En tercer lugar, se estableció el objetivo de promover la interacción directa con el ciudadano. Destacamos esta idea por sus consecuencias prácticas, puesto que las instituciones europeas seguirían percibiendo a los medios de comunicación como un intermediario importante para llegar a la población, pero no el único. La tecnología facilitaría la interacción directa entre instituciones y ciudadanos.

Y, en cuarto lugar, se propuso avanzar en la creación de una esfera pública europea. La esfera pública es el espacio social que, en los regímenes democráticos, hace posible que «(...) aquellos, los gobernantes, sean requeridos para presentar y explicar sus propuestas de acción política; y que estos, los gobernados, se constituyan en sujeto político según, al menos, una cuádruple identidad: como partidos políticos, como organizaciones de la sociedad civil, como opinión pública y, convocada a comicios, como cuerpo electoral» ${ }^{11}$.

Se impulsaba, por tanto, que dicho espacio de discusión se produjese a escala europea, para que los ciudadanos se acostumbrasen a pensar en clave comunitaria.

En la literatura académica, es posible encontrar abundantes reflexiones sobre la posibilidad de alcanzar dicho espacio público europeo; sin embargo, hay consenso en que no se ha conseguido crear. Ello no se debe, de acuerdo con Luis Bouza, «a una ausencia de interés objetivo de las políticas de la UE para el público sino a la desconexión entre el proceso político comunitario y la opinión pública» ${ }^{12}$.

A este respecto, se estaba planteando un debate de fondo sobre si podía existir una política de comunicación eficaz mientras los ciudadanos pensasen y sintiesen, en lo relativo a la identidad, en términos nacionales. Para Francisco Seoane, el problema de la baja participación en las elecciones, las

11 Manuel Martínez Nicolás, «Agitación en el campo. Nueve ideas para la investigación sobre Comunicación Política en España», Política y Sociedad, 44, n. ${ }^{\circ} 2$ (2007): 214, http:// revistas.ucm.es/index.php/POSO/article/view/POSO0707230209A/22305

12 Luis Bouza García, «Enmarcar, narrar, convencer». Cuadernos Europeos de Deusto 55 (2016): 64, doi: 10.18543/ced-55-2016pp17-29 
cifras de desconocimiento y las de euroescepticismo no responden tanto a un gap en comunicación como a la ausencia de una esfera pública europea ${ }^{13}$.

No obstante, las instituciones identificaron que debían combinar acciones para alcanzar un espacio público europeo - como el apoyo a medios paneuropeos - con la descentralización de la información, que les permitiría aportar una perspectiva comunitaria a nivel local, regional y estatal. Se promoverían, con este propósito, los proyectos en partenariado con entidades públicas y privadas de los Estados miembros.

En resumen, tras el punto de inflexión de 2005, se proponía favorecer la coordinación entre instituciones, crear una esfera pública europea sin descuidar la nacional, y avanzar en ese camino a través de la búsqueda de más cobertura mediática y de la interacción directa con el ciudadano. Veamos cómo la Comisión y el Parlamento concretaron, para su consecución, unas estrategias específicas y adaptadas a sus instituciones.

\section{La Comisión Europea: estructura organizativa y presupuestos en comunicación}

Las características políticas de la Comisión Europea condicionan su forma de comunicar. Esta institución propone iniciativas legislativas y tiene funciones de ejecutivo comunitario. Su colegio de comisarios es mixto, no procede de un solo partido. Esto le confiere neutralidad política, lo que a menudo le ha restado el atractivo de la confrontación para los medios. Tras las elecciones europeas de 2014, su presidente fue elegido, por primera vez, teniendo en cuenta los resultados obtenidos en los comicios. Ello generó un debate que encontró, moderadamente, cobertura en los medios españoles.

\section{La estrategia de comunicación en las Comisiones Barroso (2004-2014)}

Barroso fue presidente de la Comisión durante dos periodos: de 2004 a 2009 y desde 2009 a 2014. En este tiempo, propuso la siguiente estructura organizativa $^{14}$.

${ }^{13}$ Francisco Seoane Pérez, Political communication in Europe. The cultural and structural limits of the European Public Sphere (Reino Unido: Palgrave Macmillan, 2013), 197.

14 Marta Hernández Ruiz, Políticas y Estrategias de Comunicación de la Comisión Europea. Actores y procesos desde que se aprueban hasta que la información llega a la ciudadanía española (Madrid: CEU Ediciones, 2013), 23, http://www.idee.ceu.es/Portals/0/ Publicaciones/Docuweb\%2068\%20UE.pdf 


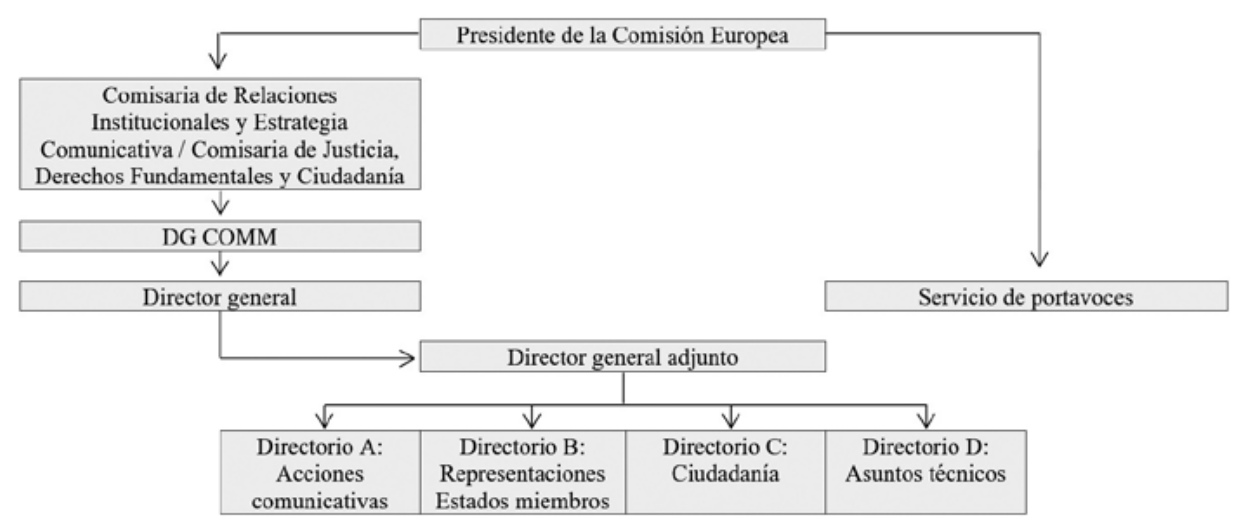

\section{Gráfico 1}

Estructura organizativa en comunicación de las Comisiones Barroso

Fuente: elaboración propia a partir de la referencia citada.

El primer rasgo que llama la atención es que la Dirección General de Comunicación (DG COMM) y el servicio de portavoces no tuviesen un mando común. La DG COMM dependía de un comisario, mientras que el servicio de portavoces lo hacía directamente del presidente.

Sorprende, en este sentido, por sus consecuencias prácticas: el servicio de portavoces centralizaba el contacto con los corresponsales y otros periodistas, pero estaba bajo una dirección diferente a todas las unidades dedicadas a la generación de contenidos proactivos (envíos de notas de prensa, creación de material audiovisual, coordinación de las representaciones...). Éstas estaban agrupadas en la DG COMM, que dependía de una comisaria dedicada a asuntos de ciudadanía ${ }^{15}$.

Esta estructura organizativa evidencia una forma de entender la comunicación institucional y unas prioridades políticas. Para profundizar en ello, es preciso preguntarse por qué la DG COMM dependía de un comisario, y no estaba, al igual que el servicio de portavoces, bajo la dirección del presidente.

15 Durante la primera etapa de Barroso como presidente (2004-2009), la DG COMM fue responsabilidad de la Comisaria de Relaciones Institucionales y Estrategia Comunicativa, Margot Wallström. Durante la segunda legislatura (2009-2014), la comunicación se agrupó con los temas de ciudadanía y se situó en el porfolio de la comisaria de Justicia, Derechos Fundamentales y Ciudadanía, cuya titular era Viviane Reding. Véase: «Communication policy», Parlamento Europeo, acceso el 12 de febrero de 2018, http://www .europarl.europa.eu/atyourservice/en/displayFtu.html?ftuId=FTU_3.6.8.html 
Para responder a esta cuestión, se introduce la siguiente reflexión que realizó Margot Wallström en 2008, cuando tenía bajo su responsabilidad la DG $\mathrm{COMM}^{16}$ :

«El no en el referéndum irlandés [en referencia a la ratificación del Tratado de Lisboa] nos dice que debemos transmitir emoción a los ciudadanos europeos al formular mensajes claros que expliquen el valor añadido de Europa, los valores comunes europeos, nuestro peso en el mundo y el coste de la no-Europa (¿qué pasaría si no hubiera una política europea de energía o de salud pública?). Estamos preparando campañas como el 20. ${ }^{\circ}$ aniversario de la caída del telón de acero, [en las] que se enfatizan los valores de libertad, paz, diversidad y solidaridad que definen nuestra historia y nuestro proyecto.»

En ese enfoque está la clave: se estimaba que el problema a solucionar era que la ciudadanía no conocía las virtudes del proyecto de integración, y por tanto, no podía simpatizar con el mismo.

Así, se tomó la decisión de desarrollar una estrategia comunicativa centrada en promocionar aquellos temas que llevasen al ciudadano a tener una opinión favorable sobre la UE: valores comunes, historia de la integración, fondos regionales, cooperación al desarrollo, etc. Y, por ello, dependería de un comisario que dirigiese una agenda hacia estos temas. Si hubiese dependido del presidente, se habría alineado la comunicación con las prioridades políticas de la Comisión. Si el objetivo era seleccionar aquellos temas que produjesen simpatía hacia la UE, tendría que contar con un comisario responsable de potenciar dicha agenda.

Mientras tanto, el servicio de portavoces tenía la misión de convertirse en el rostro de la Comisión para los corresponsales en Bruselas. Su cometido principal era luchar contra la cacofonía imperante en la institución. Hay que tener en cuenta que, sólo desde la Comisión, comunicaban activamente comisarios, portavoces y representaciones, por lo que se intentaba que los portavoces unificasen el mensaje. Sin embargo, al haber 28 portavoces, cada uno especializado en una de las 28 carteras de los comisarios, los medios consideraban que, en la práctica, cada portavoz representaba al comisario titular de la misma. No eran, como la Comisión intentaba, la voz unitaria de la Comisión ante un determinado tema.

Este enfoque continuó en la segunda legislatura de Barroso. El informe Communicating Europe to citizens and media reflexionaba, en 2012, que «the Barroso II Commission believes that communication should convey to citi-

16 Margot Wallström, «Comunicando Europa», Elpaís.com, 28 de noviembre de 2008, acceso el 12 de febrero de 2018, http://elpais.com/diario/2008/11/28/opinion/1227826805_850215.html 
zens the message that the European Union is at their service, demonstrating in concrete terms how Europe contributes to improve citizens' lives» ${ }^{17}$.

El objetivo era, por tanto, que el ciudadano pudiese ver cómo la UE tenía efectos positivos en su ámbito más cercano - se hablaba de que conociese cómo mejora su vida, no qué relevancia o papel tiene-- .

Debemos recordar, en relación con ello, que la segunda legislatura de Barroso coincidió con el estallido de la crisis económica. Se trataba de un contexto político especialmente difícil para la Comisión, y la comunicación quedó también limitada con ello: si la respuesta a la crisis económica fue, principalmente, intergubernamental ${ }^{18}$, resultaba imposible promover un mensaje de liderazgo ante los medios.

Otro punto a destacar de las Comisiones Barroso es el gran impulso que otorgaron a la generación de recursos para periodistas. Se fortalecieron servicios muy útiles como Europe by Satellite $(\mathrm{EbS})^{19}$, con el objetivo de favorecer una mayor presencia en televisión.

Por otro lado, se promovieron seminarios formativos para periodistas y las redes mediáticas paneuropeas, con proyectos como Euranet ${ }^{20}$ y Presseurop $^{21}$. En la labor directa con los ciudadanos, se desarrollaron inicativas como The Kid's Corner ${ }^{22}$, Your Europe ${ }^{23} \ldots$

17 Comisión Europea, Report: Communicating Europe to citizens and media (Bruselas: 2012), 1, http://www.europarl.europa.eu/meetdocs/2009_2014/documents/cult/dv/ europetocitizensandmedia/europetocitizensandmediaen.pdf

${ }_{18}$ Becerril Atienza, Belén, Jerónimo Maillo González-Orús y Miguel Moltó, Propuestas para el futuro de Europa: En camino hacia una Unión Económica y Política (Madrid: CEU Ediciones, 2013), 10-11, http://www.idee.ceu.es/Portals/0/Publicaciones/Docuweb\%20 Informe\%20IEE.pdf

19 EbS es el servicio informativo de la Unión Europea para televisión, dedicado a proporcionar material audiovisual a los medios de comunicación. Más información en: «What is Europe by Satellite?», Comisión Europea, acceso el 12 de febrero de 2018, http://ec.europa. eu/avservices/ebs/whatsebs.cfm?sitelang=en

${ }^{20}$ Euranet es un consorcio de radios de todos los Estados miembros que promueven noticias europeas. Más información en: «The leading radio network for EU news», Euranetplus, acceso el 12 de febrero de 2018, http://euranetplus-inside.eu/euranetplus-network/

${ }^{21}$ Se trata de un portal de noticias multilingüe que recopilaba piezas sobre la Unión Europea y las traducía a distintos idiomas. Estuvo vigente de 2009 a 2013, fecha en la que cesó el apoyo financiero institucional. En 2014, se reanudó el proyecto en el portal voxeurop.eu. Como se explica en la propia web, está conducido por un equipo de voluntarios. Pervive por las donaciones de los lectores. Véase: «Ayude a sostener Voxeurop», Voxeurop, acceso el 12 de febrero de 2018, http://www.voxeurop.eu/es

22 Espacio web para niños, con juegos y pasatiempos sobre el proceso de integración europeo. Véase: «Zona infantil. Juegos y pasatiempos sobre la UE», Europa.eu, acceso el 12 de febrero de 2018, http://europa.eu/kids-corner/index_es.htm

23 Servicio dedicado a la ayuda y asesoramiento para los ciudadanos de la UE y sus familias. Para más información, véase: «Tu Europa», Europa.eu, acceso el 12 de febrero de 2018, http://europa.eu/youreurope/citizens/index_es.htm 
Asimismo, las Comisiones Barroso se alinearon con las políticas genéricas previamente mencionadas y volvieron a hacer un llamamiento a la cooperación, tanto a nivel interno de la Comisión como interinstitucional, como se explica en el informe Communicating Europe to citizens and media $^{24}$. A nivel interno, lo hicieron mediante la coordinación con otras direcciones generales. Y, a nivel interinstitucional, a través de la puesta en marcha del llamado Inter-Institutional Group on Information (IGI), dedicado a establecer un marco común de propuestas temáticas, diseñado por un grupo de alto nivel.

Para el 2012, por ejemplo, las prioridades fueron la recuperación económica, la construcción de una Europa para los ciudadanos y sacar el máximo partido a las políticas internas y externas de la UE. Cada institución podría adaptarlas a sus propias agendas. Sin embargo, cabe destacar que, en la puesta en práctica de este objetivo de mejorar la coordinación del mensaje interinstitucional, nunca se pretendió unificar el mensaje que se lanzaba en nombre de la Unión Europea. Como cada institución tenía competencias claramente diferenciadas, intentar homogeneizar el mensaje supondría distorsionar la realidad del proceso de toma de decisiones.

Cabe mencionar, además, la importancia que adquirió la descentralización durante las Comisiones Barroso, que se mantendría con Juncker. La Comisión quería que el contacto con ciudadanos y medios fuese sencillo a nivel europeo, nacional, regional y local. Como consecuencia de la crisis económica, cada vez había menos corresponsalías en Bruselas. Las representaciones debían complementar el esfuerzo comunicativo que la institución hacía desde Bruselas, dando visibilidad a las acciones desarrolladas por la UE a nivel nacional, regional y local, interaccionando tanto con los medios como directamente con los ciudadanos ${ }^{25}$.

Por tanto, la Representación de la Comisión en los Estados miembros adquirió una importancia notable. El siguiente gráfico ${ }^{26}$ expone la estructura de la Representación en España que ya existía en las legislaturas de Barroso, y que continuó en la Comisión Juncker ${ }^{27}$ :

${ }^{24}$ Comisión Europea, Report: Communicating Europe to citizens and media (Bruselas: 2012), 8, http://www.europarl.europa.eu/meetdocs/2009_2014/documents/cult/dv/ europetocitizensandmedia/europetocitizensandmediaen.pdf

${ }_{25}$ Comisión Europea, Report: Communicating Europe to citizens and media (Bruselas: 2012), 3-4, http://www .europarl.europa.eu/meetdocs/2009_2014/documents/cult/dv/europetocitizensandmedia/europetocitizensandmediaen.pdf

26 «Contacto», Representación de la Comisión Europea en España, acceso el 12 de febrero de 2018, https://ec.europa.eu/spain/about-us/contact_es

27 Sólo incluimos los cargos y secciones relacionadas con la comunicación. 
En la Representación de la Comisión en España existe una sede central en Madrid y otra en Barcelona. En ambos casos, hay una diferenciación de las tareas comunicativas dirigidas directamente al ciudadano y aquellas centradas en los medios de comunicación.

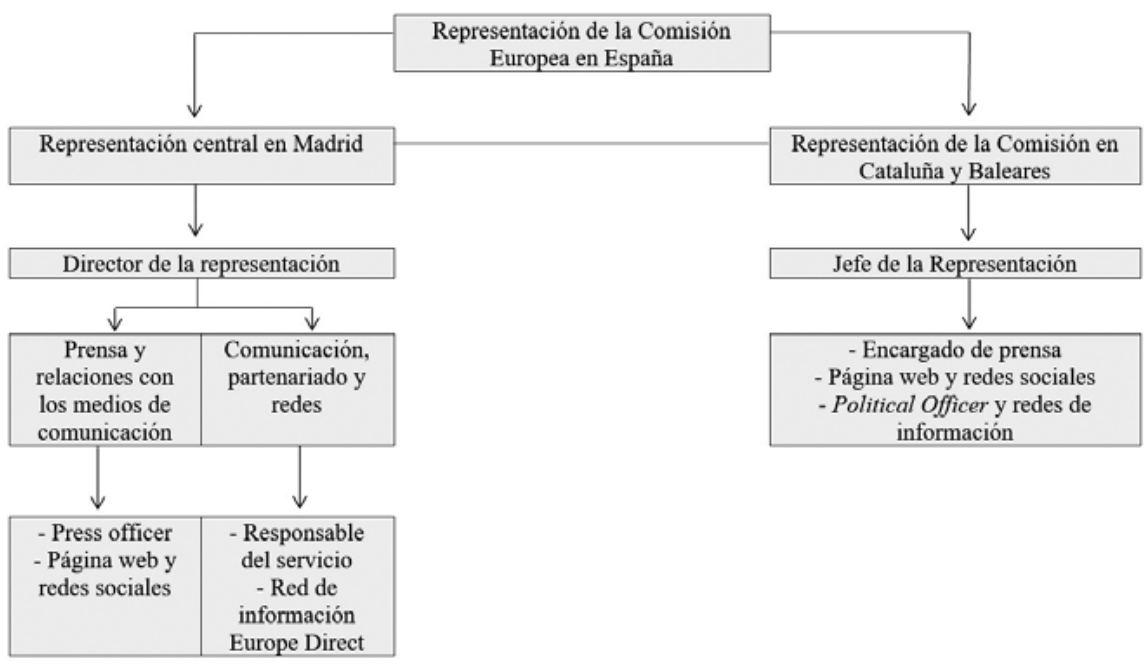

\section{Gráfico 2}

Estructura organizativa en comunicación de la Representación de la Comisión Europea en España

Fuente: elaboración propia a partir de la referencia citada.

La Representación tiene la labor de «explicar cómo pueden afectar las políticas de la UE a los ciudadanos españoles» y «ser una fuente de información sobre la UE para el Gobierno, las administraciones y las partes interesadas en España ${ }^{28}$. Interacciona directamente con los ciudadanos a través de la coordinación de los puntos informativos de Europe Direct ${ }^{29}$,

28 «Quiénes somos», Representación de la Comisión Europea en España, acceso el 12 de febrero de 2018, https://ec.europa.eu/spain/about-us_es

${ }_{29}$ Cualquier ciudadano puede acudir a estos centros para preguntar sobre sus derechos en la UE, obtener invitaciones a los actos locales sobre la UE, publicaciones y datos de contacto de organizaciones, entre otras cuestiones. Véase: «Puntos de contacto en su país», Europa.eu, acceso el 12 de febrero de 2018, https://europa.eu/european-union/contact/meet-us_es 
los Centros de Documentación ${ }^{30}$, las campañas de comunicación o la cesión de instalaciones para actividades comunicativas. En lo relativo a los medios, adopta iniciativas proactivas y reactivas hacia ellos, adapta sus contenidos a las necesidades específicas que identifica y también a las prioridades que la institución establece para el país del que se trate. Desarrolla, además, una labor de coordinación con el servicio de portavoces diaria, con el objetivo de evitar contradicciones al ir descentralizando la información.

El modelo comunicativo de Barroso hizo importantes avances en la descentralización de la información, y también estableció cauces directos para informar y escuchar a la ciudadanía. A modo de conclusión, aportamos una reflexión final que desarrollamos en un estudio publicado en $2013^{31}$ sobre las políticas comunicativas del presidente Barroso, y en el que incorporábamos una serie de entrevistas a corresponsales en Bruselas $^{32}$ :

«Existe la impresión [entre los periodistas consultados] de que, tras tomarse las grandes decisiones políticas en el seno de la Unión, las instituciones se encargan de afrontar su tarea comunicativa orientándose hacia la propaganda, utilizando a los medios como un mecanismo de reverberación de comunicados (...).

Con ello, se entra en un ciclo que les aleja de la población, se traduce en pasividad y hostilidad, y en última instancia, siguiendo el proceso circular, la ciudadanía no puede entender la institución en profundidad sólo con la información propagandística que, según los periodistas entrevistados, se les envía. En el mismo sentido se actúa con los corresponsales. Se les manda activamente datos y comunicados, pero éstos no consideran que esta práctica sea necesariamente positiva a la hora de trasladar información útil a los lectores. Se entra, así, en un problema de credibilidad. La Comisión ha quedado devaluada de cara a los periodistas a raíz de su conducta en la crisis económica, que consideran que ha ido por detrás de los Estados.»

${ }^{30}$ Los ciudadanos pueden adquirir, en estos centros, publicaciones oficiales y documentos de la UE. Asimismo, los estudiantes pueden formarse en cómo investigar cuestiones relacionadas con la UE.

${ }^{31}$ Hernández Ruiz, Políticas y Estrategias de Comunicación de la Comisión Europea... 42.

32 Esta reflexión está basada en varias entrevistas, entre las que figuran Enrique Serbeto, corresponsal del periódico ABC en Bruselas, realizada el 29 de febrero de 2012; y Ricardo Martínez de Rituerto, corresponsal del periódico El País en Bruselas, el 20 de marzo de 2012. Pueden consultarse las transcripciones íntegras en el apéndice documental de la publicación citada. 


\section{La estrategia de comunicación en la Comisión Juncker (2014-)}

La transición a la Comisión Juncker, en 2014, traería consigo algunas continuidades, pero también reformas. Esta Comisión partía con una legitimidad democrática sin precedentes hasta el momento: Juncker fue designado presidente a partir de los resultados de las elecciones europeas, lo que le otorgaba unas posibilidades que no tardó en plasmar en la estructura comunicativa. La exponemos a continuación ${ }^{33}$.

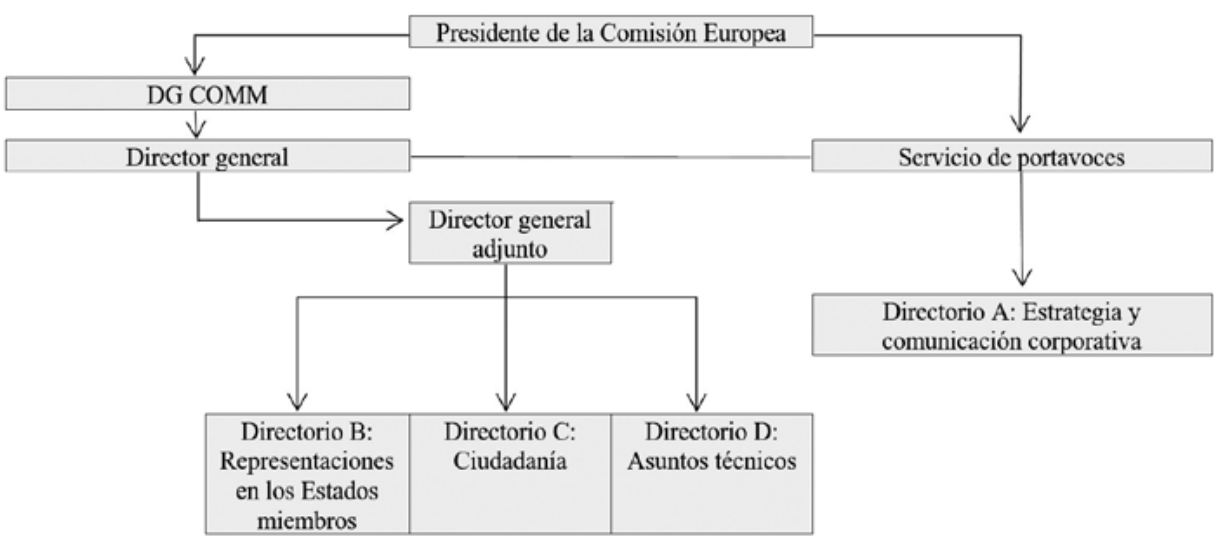

\section{Gráfico 3}

Estructura organizativa en comunicación de la Comisión Juncker

Fuente: elaboración propia a partir de la referencia previamente citada.

El principal cambio a resaltar respecto a las Comisiones Barroso es que la Dirección General de Comunicación pasó a depender directamente del presidente de la Comisión. Esta modificación entró en vigor el 1 de noviembre de 2014, y suponía un cambio en el objetivo de la estrategia de comunicación. A partir de entonces, el propósito último sería comunicar las diez prioridades políticas de la nueva Comisión Europea $^{34}$.

${ }^{33}$ Comisión Europea, Organization chart of the Directorate-General of Communication (Bruselas: 2016), http://ec.europa.eu/dgs/communication/pdf/organigramme_en.pdf

34 Comisión Europea, Strategic Plan 2016-2020. DG Communication (Bruselas: 2016), 3, http://ec.europa.eu/atwork/synthesis/amp/doc/comm_sp_2016-2020_en.pdf 
Suponía un cambio central en el enfoque: de priorizar los temas que pudieran llevar a la ciudadanía a simpatizar con la UE a promover las diez prioridades políticas transversales que guiaban el esfuerzo de toda la institución ${ }^{35}$. El presidente Juncker quería una Comisión más política que las anteriores y decidió plasmar este objetivo en la estructura comunicativa. En el documento Strategic Plan 2016-2020, destinado a la actividad de la DG COMM, se explicaba del siguiente modo: «The European Union should be bigger and more ambitious on big things, and smaller and more modest on small things. The Commission's communication needs to match this, by focusing on the 10 policy areas which have been outlined in the Political Guidelines» ${ }^{36}$.

Por su parte, el servicio de portavoces sigue dependiendo directamente del presidente, y remite informes para coordinarse con la DG COMM. Su misión continúa siendo establecer acciones de comunicación proactivas y reactivas, «with the overall purpose to provide the media with clear, accurate, comprehensive and timely information via all media channels» ${ }^{37}$.

Hay que resaltar, además, que actualmente el equipo de portavoces ${ }^{38}$ está formado por 19 miembros $^{39}$, lo que supone un descenso sustancial respecto a las Comisiones Barroso, en las que estaba constituido por 28. Esta decisión intenta evitar que cada portavoz se pueda identificar con un comisario y el equipo sea considerado la voz oficial y unitaria de la Comisión. Así, cuando se comunica sobre un determinado tema, intervienen los portavoces cuya especialización tiene alguna incidencia en la noticia que se intenta promover.

Esto mejora la coordinación entre los miembros del equipo, puesto que obliga a los portavoces a estar en contacto continuo. Sin embargo, también

${ }^{35}$ Las diez prioridades son: Empleo, crecimiento, inversión; Mercado único digital; Unión de la Energía y clima; Mercado interior; Unión Económica y Monetaria; Empleo, crecimiento, inversión; Acuerdo de libre comercio UE-EE.UU.; Justicia y derechos fundamentales; Migración; La UE, actor en el escenario mundial, y Cambio democrático. Información extraída de: «Las prioridades de la Comisión Europea», Comisión Europea. acceso el 12 de febrero de 2018, http://ec.europa.eu/index_es.htm

${ }^{36}$ Comisión Europea, Strategic Plan 2016-2020. DG Communication (Bruselas: 2016), 6, http://ec.europa.eu/atwork/synthesis/amp/doc/comm_sp_2016-2020_en.pdf

37 Comisión Europea, Strategic Plan 2016-2020. DG Communication (Bruselas: 2016), 3, http://ec.europa.eu/atwork/synthesis/amp/doc/comm_sp_2016-2020_en.pdf

38 «Press contacts - Spokesperson's Service», Comisión Europea, acceso el 12 de febrero de 2018, http://ec.europa.eu/dgs/communication/about/contact_us/ec_spokespersons/alphaindex_en.htm\#Spokespersons

${ }_{39}$ Incluimos como parte del equipo a un portavoz principal, un portavoz principal adjunto, un portavoz del portavoz principal adjunto, dos coordinadores de portavoces y 14 portavoces. 
complica la relación con los corresponsales, que pueden encontrar más difícil identificar al portavoz al que deben contactar.

Por último, y como ocurría anteriormente, las representaciones continuaron asumiendo la responsabilidad de comunicar desde una perspectiva multinivel (actuando en el ámbito nacional, regional y local). En este aspecto, predomina la continuidad.

\section{Presupuesto de la Dirección General de Comunicación de la Comisión Europea}

El presupuesto de la DG COMM determina la estrategia real que puede seguir la institución para alcanzar los objetivos comunicativos enunciados. Presentamos a continuación la evolución de los presupuestos de la DG COMM desde 2012 a $2018^{40}$.

40 Comisión Europea, Commission decision concerning the adoption of 2012 work programme in the field of Communication, serving as a financing decision (Bruselas: 2011), http://ec.europa.eu/dgs/communication/contracts-and-grants/ annual_work_programme/awp/progr2012_en.pdf; Comisión Europea, Commission decision of 18.12.2012 concerning the adoption of the 2013 work programme in the field of Communication, serving as a financing decision (Bruselas: 2012), http:// ec.europa.eu/dgs/communication/contracts-and-grants/annual_work_programme/awp/ c-2012-9486-decision-workprogramme2013_en.pdf; Comisión Europea, Annex to the Commission decision concerning the adoption of the 2014 work programme in the field of Communication, serving as a financing decision (Bruselas: 2013), http:// ec.europa.eu/dgs/communication/contracts-and-grants/annual_work_programme/awp/ c-2013-8459-work-programme2014-annex_en.pdf; Comisión Europea, Annex to the Commission decision concerning the adoption of the 2015 work programme in the field of Communication, serving as a financing decision (Bruselas: 2014), http://ec.europa. $\mathrm{eu} / \mathrm{dg}$ s/communication/contracts-and-grants/annual_work_programme/awp/c20149492-workprogramme2015-communication-annex_en.pdf; Comisión Europea, Annex to the Commission decision concerning the adoption of the 2016 work programme in the field of Communication, serving as a financing decision (Bruselas: 2015), http:// ec.europa.eu/dgs/communication/contracts-and-grants/annual_work_programme/awp/ c-2015-9059-work-programme2016-annex_en.pdf; Comisión Europea, Annex to the Commission decision concerning the adoption of the 2017 work programme in the field of Communication, serving as a financing decision (Bruselas: 2016), https:// ec.europa.eu/info/sites/info/files/work-programme2017annex-dgcomm_december2016_ en.pdf; Comisión Europea, Annex to the Commission decision concerning the adoption of the 2018 work programme in the field of Communication, serving as a financing decision (Bruselas: 2017), https://ec.europa.eu/info/sites/info/files/2018-annual-workprogramme_annex_to_wp-2018-c2017-8516_dg-comm_en_0.pdf 


\section{Tabla 1}

Presupuesto de la DG COMM de la Comisión Europea entre 2012 y 2018

\begin{tabular}{|c|c|c|c|c|c|c|c|}
\hline Concepto & 2012 & 2013 & 2014 & 2015 & 2016 & 2017 & 2018 \\
\hline Acciones multimedia. & 30.460 .000 & 28.400 .000 & 18.740 .000 & 650.000 & - & & - \\
\hline $\begin{array}{l}\text { Información para los me- } \\
\text { dios y producciones audio- } \\
\text { visuales. }\end{array}$ & - & - & - & - & 6.003 .500 & 6.177 .000 & 6.190 .000 \\
\hline $\begin{array}{l}\text { Información para los me- } \\
\text { dios. }\end{array}$ & 4.950 .000 & 5.150 .000 & 5.080 .000 & 5.200 .000 & - & & - \\
\hline $\begin{array}{l}\text { Operabilidad de los estu- } \\
\text { dios de radio y televisión } \\
\text { y de los equipos audiovi- } \\
\text { suales. }\end{array}$ & 6.755 .000 & 5.553 .000 & 5.324 .000 & 5.560 .000 & 5.560 .000 & 5.700 .000 & 5.600 .000 \\
\hline Puntos de información. & 13.755 .000 & 13.800 .000 & 14.230 .000 & 14.260 .000 & 14.600 .000 & 14.700 .000 & 15.500 .000 \\
\hline $\begin{array}{l}\text { Comunicación de las Re- } \\
\text { presentaciones de la Comi- } \\
\text { sión y acciones en parte- } \\
\text { nariado. }\end{array}$ & - & - & 10.730 .000 & 11.794 .000 & - & & - \\
\hline $\begin{array}{l}\text { Comunicación de las repre- } \\
\text { sentaciones de la Comisión, } \\
\text { diálogos ciudadanos y ac- } \\
\text { ciones en partenariado. }\end{array}$ & - & - & - & - & 14.745 .000 & 17.036 .000 & 18.357 .000 \\
\hline Espacios públicos europeos & & 1.300 .000 & 1.246 .000 & 1.246 .000 & 1.246 .000 & 1.246 .000 & 1.246 .000 \\
\hline $\begin{array}{l}\text { Comunicación de las Re- } \\
\text { presentaciones. }\end{array}$ & 8.310 .000 & 7.226 .000 & - & - & - & & - \\
\hline $\begin{array}{l}\text { Comunicando Europa en } \\
\text { partenariado. }\end{array}$ & 12.700 .000 & 12.500 .000 & - & - & - & & - \\
\hline Análisis de opinión pública. & 6.150 .000 & 6.600 .000 & 6.300 .000 & 6.400 .000 & 6.640 .000 & 6.640 .000 & 6.900 .000 \\
\hline $\begin{array}{l}\text { Información On-line y es- } \\
\text { crita y herramientas de co- } \\
\text { municación. }\end{array}$ & 14.380 .000 & 16.860 .000 & 18.180 .000 & 21.340 .000 & 23.450 .000 & 23.710 .000 & 21.300 .000 \\
\hline $\begin{array}{l}\text { Publicaciones escritas para } \\
\text { uso general (2012-2014) // } \\
\text { Informes generales y otras } \\
\text { publicaciones (2015-2018). }\end{array}$ & 2.700 .000 & 2.300 .000 & 2.200 .000 & 2.200 .000 & 2.160 .000 & 2.160 .000 & 2.160 .000 \\
\hline $\begin{array}{l}\text { Servicio de visitas // Visitas } \\
\text { a la Comisión. }\end{array}$ & 2.970 .000 & 4.000 .000 & 3.600 .000 & 3.650 .000 & 3.800 .000 & 3.900 .000 & 4.000 .000 \\
\hline Total & 103.130 .000 & 103.689.000 & 85.630 .000 & 72.300 .000 & 78.204 .500 & 81.269 .000 & 81.253 .000 \\
\hline
\end{tabular}

Fuente: elaboración propia a partir de los datos obtenidos en los informes referenciados. 
El primer rasgo a destacar es que las partidas que están dedicadas a promover contenidos en los medios de comunicación han ido decreciendo respecto al total de la Dirección General $^{41}$. Puede comprobarse si se comparan los datos año a año:

- En 2012, la ratio entre las partidas dedicadas a los medios y el total era de un $48,87 \%$ (48.875.000/103.130.000).

- En 2013, decreció a un 44,05\% (46.613.000/103.689.000).

- En 2014, continuó esta tendencia con un 41,42\% (35.472.000 / 85.630.000).

- En 2015, con la entrada de la Comisión Juncker, se produjo el descenso más acusado, con una proporción del 24,66\% (17.830.000 / 72.300.000).

Esta tendencia siguió acentuándose en los años posteriores: en 2016, un 23,02\% (18.003.500 / 78.204.500); en 2017, un 21,13\% (17.177.000 / 81.269.000); y, en 2018, un $20,46 \%$ (16.630.000 / 81.253.000).

Podemos explicar esta caída sustancial con la primera partida de la tabla: se pasó de un presupuesto de 30.460 .000 euros para «acciones multimedia» en 2012 a 650.000 euros en 2015, y posteriormente, a la eliminación de la partida.

Este cambio se debe a que esa partida contenía casi 10 millones de euros anuales dedicados a establecer redes paneuropeas de radio e internet y unos 20 millones de euros destinados a uno de los grandes proyectos de televisión pública paneuropea: Euronews.

Hasta 2014, Euronews perteneció a un consorcio formado por una veintena de canales públicos de diferentes países, tanto miembros de la UE como, en algunos casos, extracomunitarios. Analiza Ramón Reig que, «al tener tantos dueños públicos que carecen de una postura común en asuntos internos y externos (...), el periodismo sale ganando por cuanto sus contenidos carecen de intencionalidades claras» ${ }^{42}$.

Euronews era, por tanto, un ambicioso proyecto de televisión pública paneuropea. La Comisión Europea, consciente de ello, llegó a un acuerdo económico para que Euronews desarrollase su «misión de realizar información europea», como recogen Iñaki GarciaBlanco y Stephen Cushion citando al Servicio Audiovisual de la Comisión ${ }^{43}$.

Estos autores explicaban, en 2010, cuando el accionariado de la cadena era 100\% público, lo siguiente:

${ }^{41}$ Hemos identificado que son partidas directamente relacionadas con los medios las siguientes: acciones multimedia; información para los medios y producciones audiovisuales; información para los medios; operabilidad de los estudios de radio y televisión y de los equipos audiovisuales; análisis mediático (en la partida «análisis de la opinión pública»); sitios web y publicaciones electrónicas y en papel y newsletters de las Representaciones (en la partida «información on-line y escrita y herramientas de comunicación»); bases de datos de notas de prensa y otros sistemas de comunicación on-line / RAPID (en la partida «Información On-line y escrita y herramientas de comunicación»).

${ }^{42}$ Ramón Reig, Los dueños del periodismo: claves de la estructura mediática mundial y de España (Barcelona: Gedisa, 2011), 91.

${ }^{43}$ Iñaki García Blanco y Stephen Cushion, «A partial Europe without citizens or eu-level political institutions. How far can Euronews contribute to a European Public Sphere?» Journalism Studies, 11, n. ${ }^{\circ} 3$ (2010): 394-395, doi: 10.1080/14616700903378653 
«In Euronews' own promotional material, it is openly claimed that an 'editorial policy prefigures that of a European public service' (...). In a letter to the President of the European Parliament, Euronews' chairman, Philippe Cayla, has expressed satisfaction at being "an important tool", in the European Parliament's communication policy.»

Sin embargo, las dificultades de la crisis económica llevaron a algunas televisiones públicas estatales a desinvertir en Euronews, y en 2015, se decidió incorporar en el accionariado a grupos mediáticos privados. Actualmente, el $60 \%$ de la cadena es propiedad de Media Globe Networks, que posee el empresario egipcio Naguib Sawiris ${ }^{44}$, el $25 \%$ es de NBC, y el resto (15\%) es propiedad de televisiones públicas de varios países ${ }^{45}$. Entre este accionariado minoritario, podemos destacar la presencia de capital de países que no son miembros de la UE como Algeria, Rusia, Suiza, Túnez, Egipto, Ucrania y Marruecos ${ }^{46}$.

La Comisión Europea ha continuado aportando apoyo financiero a la cadena, a pesar de su carácter eminentemente privado. No obstante, Juncker ha cambiado su instrumentalización: el 10 de septiembre de 2014, el presidente manifestó al Comisario de Economía Digital y Sociedad, en su mission letter, que debería encargarse de la relación que se desarrollaba con esta cadena ${ }^{47}$. De este modo, Euronews dejó de ser una competencia de la DG COMM.

En 2015, la Comisión Europea acordó con Euronews la firma de acuerdos anuales para subvencionar proyectos concretos de la cadena desde la DG HOME. Ésta financiaría la emisión en griego, húngaro, portugués, árabe y farsi. También se desarrollarían proyectos concretos relacionados con Euronews desde otras direcciones generales, como el Servicio Europeo de Acción Exterior, que invierte 4.7 millones para el servicio farsi, así como las DG Enterprise, REGIO y ECFIN (Parlamento Europeo 2017b, 3-4).

Se distingue, de este modo, un interés en desarrollar proyectos concretos con Euronews, pero una imposibilidad de convertir esta cadena en un medio de servicio público de contenidos paneuropeos. Aunque la Comisión man-

44 Alex Spence y James Panichi, «Tycoon takeover puts Euronews funding in focus», Politico.eu, 25 de agosto de 2015, acceso el 12 de febrero de 2018, http://www.politico.eu/article/tycoon-takeover-euronews-funding-meps-commission-egypt-naguib-sawiris/

${ }^{45}$ CT (República Checa), CyBC (Chipre), ENTV (Algeria), ERT (Grecia), TT (Túnez), ERTU (Egipto), France Télévisions (Francia), NTU (Ucrania), PBS (Malta), RAI (Italia), RTBF (Bélgica), RTE (Irlanda), RTP (Portugal), RTR (Rusia), RTVSLO (Eslovenia), SNRT (Marruecos), SSR (Suiza), TVR (Rumanía), TV4 (Suecia), YLE (Finlandia), Métropole de Lyon, Département du Rhône, Région Rhône-Alpes.

46 «The media. Euronews SA. 26 Shareholders», Euronews, acceso el 12 de febrero de 2018, http://www.euronews.com/about

47 Parlamento Europeo, Research for CULT Committee - Euronews (Bruselas: 2017), 4, http://www.europarl.europa.eu/cmsdata/117126/Euronews_briefing.pdf 
tenga una inversión parecida a los años anteriores, no se pueden conseguir los mismos resultados si los accionistas son socios privados que si son públicos.

Por tanto, si el objetivo de las instituciones europeas era que esta inversión ayudase a crear una esfera pública europea, el mantenimiento de $E u$ ronews a modo de televisión pública comunitaria debería haber sido una prioridad. Podría haberse planteado entrar en su accionariado, como hizo el Parlamento Europeo durante un periodo tras la salida de ITN, en $2002^{48}$, aunque ello le hubiera obligado a reestructurar su amplio presupuesto en comunicación para aumentar su inversión en este medio. Estimamos que podría ser posible disminuir las partidas dedicadas a interaccionar directamente con la ciudadanía, cuyos fines son más formativos que informativos, en pro de la consolidación de una televisión pública paneuropea.

Este canal compite directamente con $C N N$ y $B B C^{49}$, a pesar de tener que hacerlo a través de plataformas privadas en España, por no estar presente en la TDT. Según su web corporativa, actualmente alcanza 430 millones de viviendas en 166 países $^{50}$.

Continuando con el cuadrante presupuestario, la Comisión Europea invierte unos cinco millones de euros anuales en facilitar información a los medios. Incluye partidas de generación de contenidos, seminarios especiales para periodistas, reuniones con los medios, archivos, etc. También se puede identificar una partida de casi siete millones de euros en 2012, que en años posteriores se asienta alrededor de los cinco millones y medio, destinada a proporcionar recursos audiovisuales.

Por otro lado, hay que destacar las acciones dedicadas a las representaciones y a las iniciativas en partenariado. La comunicación en partenariado se refiere a establecer socios entre los órganos públicos y privados del Estado miembro. Es, sin duda, una prioridad comunicativa, por su importancia presupuestaria (más de 18 millones de euros en 2018). En esta línea se encuentra la dotación de 1.300.000 euros que cada año se dedican a crear «Espacios públicos europeos».

Con el mismo propósito, Juncker creó los llamados «diálogos ciudadanos» en 2015. Pretendía personalizar la imagen de la institución a partir de debates directos entre comisarios y ciudadanos ${ }^{51}$. También se invitaba

\footnotetext{
48 Reig, Los dueños del periodismo..., 89.

49 Reig, Los dueños del periodismo..., 90.

50 «The media. Euronews SA. 26 Shareholders». Euronews, acceso el 12 de febrero de 2018, http://www.euronews.com/about

${ }^{51}$ Comisión Europea, Annex to the Commission decision concerning the adoption of the 2015 work programme in the field of Communication, serving as a financing decision (Bruselas: 2014), 6, http://ec.europa.eu/dgs/communication/contracts-and-grants/annual_work_ programme/awp/c2014-9492-workprogramme2015-communication-annex_en.pdf
} 
a que, en la medida de lo posible, se estableciesen sinergias con el Parlamento Europeo y los Estados miembros para su celebración.

Asimismo, en los últimos años han aumentado los recursos para la información on-line y las herramientas comunicativas. En 2012 se dedicaban unos 14 millones de euros, mientras que en los últimos tres años oscilan entre los 21 y 23 millones.

Este incremento se corresponde principalmente a la inversión en el portal Europa.eu, que pasó de cuatro millones y medio en 2012 a 10.910.000 euros en 2018. Dicho aumento se debe a la importancia que ha adquirido en los últimos años la comunicación on-line.

Desde la DG COMM, también se desarrollan acciones de análisis de la opinión pública. De este modo, se incluyen herramientas como el eurobarómetro y la unidad de análisis de monitoreo cualitativo, que permiten conocer el clima de opinión y la cobertura mediática de los asuntos europeos.

Para lograr la interacción directa con la ciudadanía, hay una importante apuesta por los centros Europe Direct. Están dotados con unos catorce millones de euros anuales.

Por último, el presupuesto dedica una cuantía de entre 2.700 .000 (2012) y 2.160 .000 (2018) a informes generales y otras publicaciones, y entre tres y cuatro millones de euros a las invitaciones para visitar la Comisión Europea.

Todos estos datos nos permiten preguntarnos a qué objetivos comunicativos dedica la institución más recursos actualmente y, por tanto, prioriza.

De este modo, es posible concluir que hay una prioridad clara de favorecer la interacción directa con el ciudadano, con tres cuartas partes del presupuesto actual destinado a ello.

Si bien es importante explorar las vías de interacción directa con el ciudadano, estimamos que, para alcanzar los objetivos determinados en las políticas comunicativas, estas partidas deberían tender a estar más equilibradas respecto a la de los medios de comunicación. Las visitas a la institución, los seminarios, los debates con comisarios, son métodos formativos para que el ciudadano entienda mejor el funcionamiento de la institución, pero alcanzan nichos de población muy pequeños.

Si la UE quiere asentarse en el día a día de los ciudadanos y que estos comprendan su papel en la actualidad, es necesario fortalecer el apoyo presupuestario destinado a que los medios de comunicación hablen con seriedad sobre las temáticas comunitarias. Además de facilitarles recursos técnicos e información proactiva y reactiva, se debería incrementar el apoyo a la creación de un medio paneuropeo público y a crear espacios especializados en los privados, para que los contenidos en clave europea lleguen a públicos masivos. 


\section{El Parlamento Europeo: estructura organizativa y presupuestos en comunicación}

\section{Estructura organizativa de la Dirección General de Comunicación del Parlamento Europeo}

Para precisar la estructura organizativa del Parlamento Europeo, debemos contextualizar primero la situación actual de la institución. El Parlamento Europeo ha protagonizado una larga lucha por incrementar su poder legislativo en cada reforma de los tratados, hasta conseguir, con el Tratado de Lisboa, formar parte del llamado Procedimiento Legislativo Ordinario, también conocido como mecanismo de codecisión. Ello le otorga la posibilidad de participar plenamente en el proceso legislativo junto al Consejo. Sin embargo, el ciudadano tiene dificultades para conocer su poder real.

El Parlamento Europeo también se ha alineado con los objetivos comunes que enumerábamos previamente. En este sentido, se ha manifestado claramente a favor de avanzar hacia la creación de una esfera pública europea $^{52}$. Para ello, estima que un primer paso sería que los ciudadanos pudieran acceder a la información pública del Consejo, la Comisión y el Parlamento Europeo en todas las lenguas de la UE.

Para Francisco Seoane, la problemática de las lenguas tiene más importancia de lo que puede parecer en apariencia, por su implicación tanto en el uso práctico de la información como en la identidad cultural del individuo. Reflexiona este autor al respecto ${ }^{53}$ :

«The students of the European public sphere often minimize the issue of language (...). As one of my interviewees recalled, the videos produced by the European Commission are spoken in an English that no British person can feel their own. A directly elected president of the EU would be a politician persuading through translation.»

Por otro lado, el Parlamento Europeo se ha alineado con la declaración Communicating Europe in Partnership de 2009, secundada por Comisión, Parlamento Europeo y Consejo, y que hacía un llamamiento a una mejor coordinación en comunicación. Tras su firma, se acordaron las prioridades interinstitucionales en materia de comunicación ${ }^{54}$.

52 Parlamento Europeo, Report on journalism and new media - creating a public sphere in Europe (2010/2015(INI)) (Bruselas: 2010), http://www .europarl.europa.eu/sides/getDoc. do?pubRef=-//EP//TEXT+REPORT+A7-2010-0223+0+DOC+XML+V0//EN

53 Seoane Pérez, Political communication in Europe..., 201.

54 «Communication policy», Parlamento Europeo, acceso el 12 de febrero de 2018, http://www .europarl.europa.eu/atyourservice/en/displayFtu.html?ftuId=FTU_3.6.8.html 
Esta institución tiene numerosas voces que emiten mensajes, si bien en este caso no se puede hablar de cacofonía, sino de posturas ideológicas diferenciadas, sobre todo en lo que concierne a la comunicación de cada diputado y cada familia política europea.

Por tanto, el cometido del equipo de comunicación institucional no es alcanzar una voz unificada. Su objetivo es explicar qué es lo que se está decidiendo en la cámara de forma divulgativa e informativa, adaptándose en lo posible al estilo de los medios o al que puede ser más eficaz cuando se intenta interaccionar directamente con la ciudadanía. Así, y de acuerdo con la web de la dirección general de comunicación, ésta tiene los siguientes objetivos ${ }^{55}$ :

- Colaborar con los medios; informar, explicar y promover la visibilidad del trabajo del Parlamento Europeo.

- Incrementar la conciencia de la labor del Parlamento Europeo entre los ciudadanos, los interesados y los líderes de opinión a través de las Oficinas de Información del Parlamento Europeo.

- Promover la interacción con los ciudadanos mediante proyectos, eventos, campañas informativas y presencia en redes sociales.

- Facilitar el asesoramiento comunicativo a los miembros del Parlamento Europeo y a los grupos políticos con servicios como el monitoreo de la opinión pública y los medios de comunicación.

Cuenta con una estructura más estable que la Comisión, ya que no está tan supeditada a los posibles cambios tras unos comicios europeos ${ }^{56}$ :

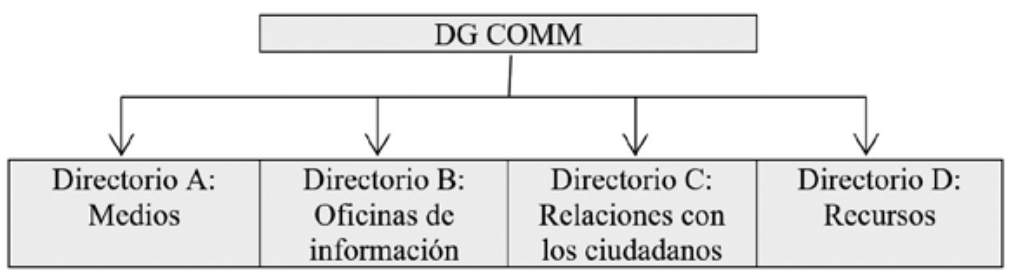

\section{Gráfico 4}

Estructura organizativa en comunicación del Parlamento Europeo

Fuente: elaboración propia a partir de la referenciada citada.

55 «Directorate-General for Communication», Parlamento Europeo, acceso el 12 de febrero de 2018, http://www.europarl europa.eu/the-secretary-general/en/organisation/ directorate-general-for-communication

56 «Directorate-General for Communication», Parlamento Europeo, acceso el 12 de febrero de 2018, http://www.europarl europa.eu/the-secretary-general/en/organisation/ directorate-general-for-communication 
De acuerdo con las explicaciones de Jaume Duch, portavoz del Parlamento Europeo y, desde diciembre de 2016, director de la dirección general ${ }^{57}$, existen dos tareas esenciales para la DG COMM: una directa, que tiene como objetivo explicar a la ciudadanía la actividad parlamentaria, y una indirecta, que se concreta en los contenidos que se destinan a los periodistas o que se exponen a través de los medios online del Parlamento Europeo.

Diferenciada de esta labor informativa, existe otra rama en la dirección general centrada en acompañar la información desde el punto de vista del marketing. Organizan eventos, campañas, gestionan los grupos de visitantes invitados por los eurodiputados, etc. Sería un trabajo menos sujeto a la actualidad. Añade Damián Castaño ${ }^{58}$ que también se invitan a varios periodistas de cada Estado miembro para que cubran los plenos, y se les abonan los gastos de transporte, hotel, etc.

Como puede verse en el gráfico, el directorio A es el que centraliza la relación con los medios de comunicación. Para gestionar esta interacción, precisa Jaume Duch que se realizan reuniones diarias de coordinación a corto, medio y largo plazo, en las que se analiza qué temas se van a tratar en el Parlamento Europeo y se organiza un plan de medios para los más importantes. Se seleccionan teniendo en cuenta que puedan causar una cierta reactividad en los medios y en la ciudadanía interesada.

Encontramos en estas explicaciones una idea clave: hay asuntos que el Parlamento Europeo considera centrales por tener más competencias en ellos y que no son del interés de los medios. El equipo de comunicación del Parlamento Europeo reconoce la necesidad de buscar un equilibrio en proponer aquellos asuntos que más interesan a los medios y los que son estratégicos para la institución. Explica Jaume Duch:

«Intentamos no imponer nuestra agenda a los medios, porque eso no funciona, sino más bien acompañamos la agenda de los medios. Es decir, los temas que está tratando el Parlamento Europeo que ya tienen de alguna manera cierta repercusión en los medios de comunicación, son los que intentamos empujar para que no se pierda el lado parlamentario.»

Esta idea también está presente en el informe anual de la institución del año 2015 ${ }^{59}$ : «Big media topics like the migrants' crisis or terrorist

57 Duch, Jaume, portavoz del Parlamento Europeo, y director de la Dirección General de Comunicación [entrevista personal] 11 de mayo de 2015.

58 Castaño, Damián, Press Officer del Parlamento Europeo [entrevista personal] 27 de mayo de 2015.

59 Parlamento Europeo, Annual Activity Report 2015. DG COMM (Bruselas: 2016), 6, http://www.europarl.europa.eu/cmsdata/104253/5_COMM_RAA2015_EN_signed.pdf 
threat and legislative files as roaming or TTIP demanded DG COMM's full commitment in order to increase awareness on the activities of the EP».

Continuando con las rutinas de esta dirección general, explica Damián Castaño que la labor práctica de este servicio consiste en preparar los documentos para los medios en 23 idiomas, dirigiendo la estrategia al momento de los plenos, que es el principal. Además, adaptan la agenda al contexto de cada país. Cuando se aproximan sesiones plenarias, hacen una lista de los temas prioritarios, se traducen y se difunden a corresponsales, redacciones centrales y a las bases de datos de medios de cada Estado miembro. Asimismo, en las semanas con comisiones parlamentarias, se estudia si hay temas que puedan interesar a los países y, si así se considera, se informa a los medios.

Por último, procedemos a explicar cómo se concreta la descentralización informativa en el caso del Parlamento Europeo. La Oficina de Información en España tiene el siguiente organigrama (Parlamento Europeo. Oficina de Información en España 2018a):

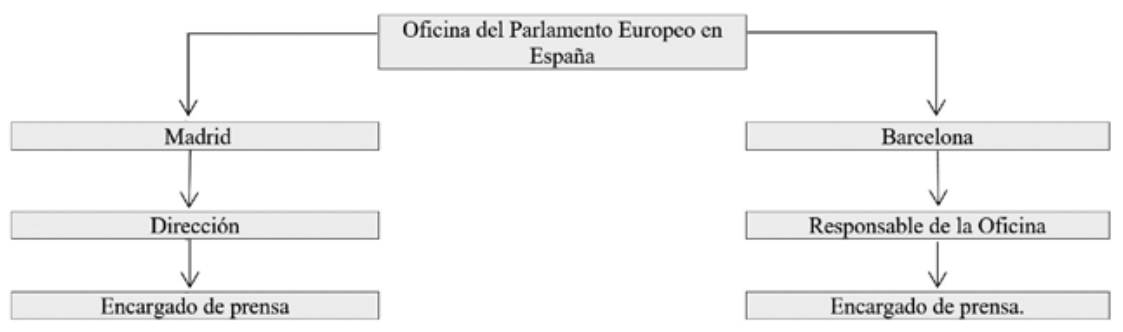

\section{Gráfico 5}

Estructura organizativa en comunicación de la Oficina del Parlamento Europeo en España

Fuente: elaboración propia a partir de la referencia citada.

Esta Oficina cuenta con menos recursos humanos y financieros que la Representación de la Comisión, tanto en Madrid como en Barcelona, puesto que sus funciones están mucho más delimitadas que en el caso de la Comisión (Parlamento Europeo. Oficina de Información en España 2018a).

Como recoge la web de la Oficina, el cometido de ésta es proporcionar «un servicio abierto a todos los ciudadanos que desean o necesitan conocer la información y actividades del Parlamento Europeo y de los eurodiputados españoles» 60 .

60 «Oficinas en España», Parlamento Europeo. Oficina de Información en España, acceso el 12 de febrero de 2018, http://www.europarl.es/es/nuestras_oficinas.html;jsessionid= 02C5262899FB7EA7DA645D0BD0BB007D 
Destacamos dos tareas principales: por un lado, facilitar información a los ciudadanos, responder a las dudas y atender las sugerencias. Y, por otro lado, promover contenidos de la institución en los medios de comunicación nacionales. En este sentido, se difunden noticias y comunicados de prensa a los medios españoles, se facilita el seguimiento a los plenos y las actividades de los diputados, se organizan conferencias de prensa, etc.

\section{Presupuesto de la Dirección General de Comunicación del Parlamento Europeo}

Recopilamos en la tabla $2^{61}$ los presupuestos de la Dirección General de Comunicación del Parlamento Europeo entre los años 2012 y $2016^{62}$.

Veníamos señalando que había un objetivo común de interaccionar directamente con el ciudadano y otro de promover contenidos en los medios. También que, en la Comisión Europea, ambas partidas pasaron de estar equilibradas a favorecer la interacción directa.

En el caso del Parlamento Europeo, dicha tendencia es también acusada. Basamos esta afirmación en los siguientes datos ${ }^{63}$ :

- En 2012, el 35,25\% del presupuesto se dedicó a los medios de comunicación (31.970.000/90.692.650).

- En 2013, fue un 33,20\% (35.464.200/106.787.900).

- En 2014, un 29,49\% (30.250.000/102.550.435).

- En 2015, un 27,47\% (25.336.000/92.205.193).

- Y, en 2016, 30.02\% (27.787.600/92.559.100).

61 Parlamento Europeo, Annual Activity Report 2012. DG Communication (Bruselas: 2013), http://www.europarl.europa.eu/document/activities/cont/201309/20130911AT T71096/20130911ATT71096EN.pdf; Parlamento Europeo, Annual Activity Report 2013. DG Communication (Bruselas: 2014), http://www .europarl.europa.eu/cmsdata/58960/att _20141113ATT93210-4417119662789132956.pdf; Parlamento Europeo, Annual Activity Report 2014. DG Communication (Bruselas: 2015), http://www.europarl.europa.eu/cmsdata/87968/COMM_RAA2014_EN_dec\%20signed.pdf; Parlamento Europeo, Annual Activity Report 2015. DG COMM; Parlamento Europeo, Annual Activity Report 2016. DG COMM (Bruselas: 2017), http://www.europarl.europa.eu/cmsdata/125729/5_COMM_RAA2016_ CONSOLIDATED_EN_signed.pdf

62 El informe de gastos de 2016 es el último disponible en la web del Parlamento Europeo. Las cifras aportadas están basadas en las partidas presupuestadas al inicio del año.

${ }_{63}$ Consideramos partidas relacionadas con medios de comunicación las siguientes: materiales e instalaciones técnicas: audiovisual, compra, renovación, mantenimiento; suscripciones, monitoreo mediático; canal de televisión parlamentaria (Web TV) y gastos de información audiovisual. 


\section{Tabla 2}

Presupuesto de la DG COMM del Parlamento Europeo entre 2012 y 2016

\begin{tabular}{|c|c|c|c|c|c|}
\hline Concepto & 2012 & 2013 & 2014 & 2015 & 2016 \\
\hline Obras de arte. & 240.000 & 90.000 & 80.000 & 82.000 & 80.000 \\
\hline $\begin{array}{l}\text { Materiales e instalaciones técni- } \\
\text { cas: audiovisual, compra, renova- } \\
\text { ción, mantenimiento. }\end{array}$ & 8.050 .000 & 6.300 .000 & 6.975 .000 & 5.643 .000 & 6.286 .600 \\
\hline $\begin{array}{l}\text { Suministros, material de oficina, } \\
\text { otros suministros. }\end{array}$ & 85.000 & 65.500 & 60.000 & 40.000 & 20.000 \\
\hline Casa de la Historia Europea. & 200.000 & 200.000 & 200.000 & - & - \\
\hline $\begin{array}{l}\text { Suscripciones, monitoreo mediá- } \\
\text { tico. }\end{array}$ & 660.000 & 1.030 .500 & 2.655 .000 & 2.085 .000 & 1.995 .000 \\
\hline
\end{tabular}

Gastos de publicación de información y participación en eventos públicos.

Centro de visitas al Parlamento

$\begin{array}{llllll}\text { Europeo. } & 3.600 .000 & 3.916 .000 & 4.978 .023 & 4.150 .000 & 6.030 .000\end{array}$

Organización y acuerdos con grupos de visitantes, programa Euroscola e invitaciones a multiplicadores de opinión de terceros países.

Subvenciones para organizar conferencias, seminarios nacionales y actividades multiplicadoras de opinión en los Estados miembros; organización de conferencias y

\begin{tabular}{lrrrrc} 
simposios parlamentarios. & 2.796 .650 & 5.078 .800 & 4.950 .000 & 3.867 .120 & 4.435 .000 \\
\hline $\begin{array}{l}\text { Premio para el cine. } \\
\text { Canal de televisión parlamentaria } \\
\text { (Web TV). }\end{array}$ & 600.000 & 552.000 & 455.000 & 400.000 & - \\
\hline
\end{tabular}

Casa de la Historia Europea: Gastos de la DG COMM. $\begin{array}{lllll}- & 6.400 .000 & 9.650 .000 & 10.000 .000 & 6.500 .000\end{array}$

Gastos de información audiovisual.

$\begin{array}{lllll}14.760 .000 & 20.133 .700 & 15.620 .000 & 12.608 .000 & 14.506 .000\end{array}$

Gastos de las Oficinas de Información (papelería, muebles, etc.).

$\begin{array}{lllll}1.100 .000 & 1.100 .000 & 1.100 .000 & 700.000 & 900.000\end{array}$

\begin{tabular}{llllll}
\hline Total & 90.692 .650 & 106.787 .900 & 102.550 .435 & 92.205 .193 & 92.559 .100 \\
\hline
\end{tabular}

Fuente: elaboración propia a partir de los informes referenciados. 
Cabe preguntarnos, por tanto, si las partidas dedicadas a promover contenidos en los medios deben limitarse a facilitar recursos técnicos y contenidos o si, por el contrario, deberían seguir explorándose nuevas formas de impulsar la cobertura. Esta última opción iría en coherencia con el propósito de impulsar una esfera pública europea y una dimensión europea de la esfera nacional.

Hacemos, de este modo, una reflexión en coherencia con la que realizábamos en el caso de la Comisión Europea: podrían explorarse o fomentarse vías para potenciar los contenidos comunitarios en los medios, como promover un medio paneuropeo de servicio público con ayudas económicas, o impulsar mediante partenariados con medios nacionales y regionales privados la creación de espacios informativos temáticos sobre la Unión Europea.

Continuando con el análisis del presupuesto, se procede a abordar primero las partidas dedicadas a los medios de comunicación y, acto seguido, a las que están destinadas a interaccionar con la ciudadanía.

Entre las partidas dedicadas a los medios, puede distinguirse que los recursos audiovisuales han tenido una especial dimensión en el presupuesto, decisión que consideramos acertada, por su importancia para el sector. Así, el canal de televisión parlamentaria tenía en 2012 una dotación de 8.500.000 euros, aunque en 2016 tenía cinco. Esa tendencia decreciente también se percibió en la partida destinada a proporcionar recursos a los medios, desde unos ocho millones en 2012 a unos seis en 2016.

Por su parte, las partidas destinadas a las coproducciones audiovisuales oscilaron desde los 12 millones de euros en 2015 y los veinte millones en 2013, posiblemente por ser un año previo a las elecciones europeas.

Hay que resaltar también la partida destinada a suscripciones y monitoreo mediático, que adquirió una importancia central en 2014, año de las elecciones europeas. Pasó, de este modo, de 660.000 euros en 2012 a 2.655.000 en 2014. Un año después decreció moderadamente hasta los 2.085.000.

Por otro lado, agrupamos las partidas dedicadas a interaccionar con la ciudadanía. Una de las más importantes es la relativa a los gastos de publicación y de participación en eventos públicos, que ha estado en torno a los veinte millones de euros anuales, aunque con tendencia al descenso en 2016 (16 millones).

También, en esta línea, se encuentra la partida de subvenciones para organizar conferencias, seminarios nacionales, simposios parlamentarios, etc. El objetivo es favorecer el debate sobre temas estratégicos para la institución con los ciudadanos, y están dotados de entre dos millones y medio y cinco millones anuales, dependiendo del año.

El centro de visitas al Parlamento Europeo tuvo su máximo en 2016, con seis millones de euros, claramente superior a los años previos. Destaca, en 
relación con esto, la partida destinada a invitar a grupos de visitantes, que ha contado con unos 30 millones de euros anuales, y que se ha dedicado a sufragar los gastos de distintos colectivos para que conozcan la institución.

Por último, se encuentran varias partidas que, aunque están sufragadas por esta dirección general, tienen un propósito didáctico o cultural: la Casa de la Historia Europea, los premios al cine, la compra de obras de arte, etc.

\section{Conclusiones}

En el presente trabajo, hemos identificado los objetivos principales de la estrategia de comunicación de la Unión Europea desde el rechazo al Tratado Constitucional. Asimismo, hemos analizado la estructura organizativa y el presupuesto que la Comisión y el Parlamento Europeo han destinado para conseguirlos. Exponemos a continuación las principales conclusiones alcanzadas.

El primer objetivo que se identificó fue mejorar la coordinación interinstitucional en materia de comunicación. Se perseguía con ello que hubiese más coherencia en el mensaje que las distintas instituciones emitían en nombre de la UE.

Este propósito favoreció que se realizasen esfuerzos en la estructura organizativa, como el establecimiento del grupo de trabajo Inter-Institutional Group on Information, en el que se designaba un marco común de prioridades temáticas, o la declaración Communicating Europe in Partnership, secundada por Comisión, Parlamento Europeo y Consejo.

No obstante, es preciso aclarar que, en la práctica, dicho esfuerzo se restringió a una cierta labor de coordinación. En este sentido, estimamos que deberían continuar desarrollándose y fortaleciéndose las reuniones de coordinación, pero sin intentar unificar el mensaje que se emite en nombre de la Unión Europea. Si bien pudiese parecer una iniciativa atractiva, puesto que los ciudadanos y los medios entenderían mejor el proceso de integración, simplificaría tanto el relato sobre la toma de decisiones que acabaría faltando a la realidad.

En segundo lugar, se identificó que había que promover la cobertura mediática de los asuntos europeos. Actualmente, se dedica aproximadamente una cuarta parte de los recursos de las Direcciones Generales de Comunicación de Comisión y Parlamento Europeo a este fin. Sus acciones se concretan en la generación de recursos que puedan ser útiles a los medios de comunicación y también en proporcionarles medios técnicos para facilitar su labor.

Cabe precisar que existe una evolución en los objetivos de la Comisión respecto a los medios. En las Comisiones Barroso, el servicio de portavoces dependía directamente del presidente, mientras que la DG COMM 
lo hacía de comisarias encargadas de asuntos de ciudadanía. Ello evidencia que se pretendían impulsar especialmente los temas que pudiesen promover una mayor conciencia de los logros de la UE: valores comunes, historia de la integración, fondos regionales, cooperación al desarrollo, etc. Si hubiese dependido del presidente, la selección de temas habría tenido que alinearse con las prioridades políticas de la Comisión, aunque no promoviesen necesariamente una mayor simpatía en la ciudadanía. Y fue lo que ocurrió con la Comisión Juncker: la DG COMM pasó a depender también del presidente, con el objetivo de comunicar activamente sobre las diez prioridades políticas que guiarían su legislatura.

Juncker también intentó reducir la cacofonía y buscar la unidad del mensaje que se emitía en nombre de la Comisión mediante la reducción del equipo de portavoces, que pasó de 28 miembros (tantos como comisarios) a 19. Esta decisión intentaba evitar que cada portavoz correspondiese a un comisario. De este modo, se convertirían en las voces unitarias de la Comisión. Así, cuando se comunica sobre un determinado tema, intervienen los portavoces cuya especialización tenga alguna relación con el mismo.

En cuanto al Parlamento Europeo, su equipo de comunicación no tiene el cometido de evitar cacofonías, puesto que, en este caso, les favorece que haya debate ideológico entre las familias políticas, ya que facilita que exista una cobertura mediática. El principal desafío de su DG COMM es captar el interés de los medios en los asuntos estratégicos de la institución. Al mismo tiempo, intenta adaptarse a aquellos temas que pueden causar una mayor cobertura mediática, a pesar de que, a veces, el Parlamento Europeo tenga menor poder decisorio en ellos. Sin embargo, explicar el papel coyuntural que tiene la institución en asuntos como la política exterior de la UE ayuda a que el ciudadano conozca mejor los equilibrios institucionales y entienda el proceso de toma de decisiones.

En este sentido, estimamos que tanto la Comisión Europea como el Parlamento Europeo deben explorar más esta vía para obtener impacto mediático. Deben intentar adaptarse en lo posible a la agenda mediática y explicar las competencias que tienen en las políticas con una clara dimensión trasnacional (economía, migración, política exterior...). Además, con una comunicación valiente, estas instituciones se consolidarían aún más como fuente usual para los medios.

En tercer lugar, se pretendía reforzar la interacción directa con el ciudadano. Este ha sido, con diferencia, el objetivo más impulsado de los cuatro. Así lo demuestra que, aproximadamente, tres cuartas partes de los presupuestos de las Direcciones Generales de Comunicación del Parlamento Europeo y de la Comisión Europea vayan destinados a este fin. Se hace a través de herramientas variadas, que combinan acciones informativas (narrar la actualidad a través de redes sociales, por ejemplo), formativas (publica- 
ciones y material audiovisual sobre el funcionamiento institucional) y de marketing (visitas a la institución, campañas publicitarias, etc.).

Si bien es importante interaccionar con el ciudadano, estas acciones alcanzan nichos de población pequeños. Sería recomendable equilibrar estas partidas con las dedicadas a los medios. Principalmente, a través de fomentar contenidos en clave europea en espacios subvencionados en medios privados regionales y nacionales y de la consolidación de medios públicos paneuropeos, por su potencial para lograr una ciudadanía mejor informada.

Y, en cuarto lugar, se priorizó la creación de una esfera pública europea. Desde el rechazo al Tratado Constitucional, se concluyó que, sin ella, no podría haber una comunicación efectiva. Y en este punto se han encontrado ciertas discrepancias entre el objetivo marcado y la estructura organizativa y presupuestaria con la que se ha pretendido alcanzar.

Para crear una esfera pública europea, la Comisión invirtió importantes partidas en la creación de redes mediáticas paneuropeas. De ellas destacamos la apuesta por Euronews, que había aspirado a convertirse en una televisión de servicio público paneuropeo. Hasta 2015, su capital era 100\% público, puesto que su accionariado estaba compuesto por las radiotelevisiones públicas de una veintena de países. Además, la Unión Europea la apoyaba financieramente.

Sin embargo, se decidió privatizar Euronews en 2015. Esto conlleva necesariamente cambios en los objetivos de la cadena, y aunque la Comisión ha mantenido el apoyo presupuestario, puede afirmarse que los efectos de su inversión serán diferentes ante un accionariado privado. El apoyo que se destina en la actualidad se centra en la subvención de proyectos específicos, como la emisión en determinadas lenguas que sus accionistas actuales pueden considerar menos rentables.

Consideramos que, para alcanzar el objetivo de avanzar en la creación de una esfera pública paneuropea, las instituciones supranacionales deberían haber priorizado el mantenimiento de este canal como televisión pública, aunque hubiese supuesto un mayor reparto presupuestario a su favor respecto a las acciones destinadas, en las DG COMM, a interaccionar directamente con la ciudadanía. No habría sido necesario ampliar el presupuesto, sino redistribuir sus partidas en ambas instituciones.

A modo de conclusión final, se han establecido cuatro objetivos acertados, y se han dotado de ambiciosos presupuestos a unas DG COMM bien organizadas y que operan a nivel comunitario, estatal, regional y local.

No obstante, el camino hacia una comunicación efectiva debe continuar. Debe crearse un medio público paneuropeo y favorecer los espacios especializados en medios privados. Las instituciones supranacionales deben ser valientes en su comunicación proactiva y reactiva. No deben restringir su agenda a los temas que puedan promover una opinión favorable en el ciuda- 
dano, sino intentar que éste comprenda los pesos y contrapesos que existen actualmente en la UE. Esto puede llevar a los ciudadanos a tener una opinión negativa de determinadas decisiones, pero conseguirá, a cambio, que no cuestionen el proceso de integración ante cada situación de dificultad: entenderán en qué institución se ha producido la decisión con la que no están de acuerdo, y podrán focalizar sus críticas en la gestión de la misma.

Es importante, por tanto, que el ciudadano entienda los debates que se van a producir, de cara a las elecciones europeas de 2019, en torno a la estructura institucional y a la legitimidad democrática de la Unión. Que forme parte de la discusión que existe, por ejemplo, en torno a la elección del presidente de la Comisión. Que pueda opinar sobre si los ciudadanos deberían poder votar quién será el próximo presidente de la Comisión en esos comicios. En este sentido, una comunicación valiente y clara del Parlamento Europeo y de la propia Comisión será central.

\section{Bibliografía}

Becerril Atienza, Belén, Jerónimo Maillo González-Orús y Miguel Moltó. Propuestas para el futuro de Europa: En camino hacia una Unión Económica y Política. Madrid: CEU Ediciones, 2013. http://www.idee.ceu.es/Portals/0/ Publicaciones/Docuweb\%20Informe\% 20IEE.pdf

Bouza García, Luis. «Enmarcar, narrar, convencer». Cuadernos Europeos de Deusto 55 (2016): 61-83. doi: 10.18543/ced-55-2016pp17-29

Comisión Europea. «Las prioridades de la Comisión Europea». Acceso el 12 de febrero de 2018. http://ec.europa.eu/index_es.htm

Comisión Europea. «Press contacts - Spokesperson's Service». Acceso el 12 de febrero de 2018. http://ec.europa.eu/dgs/communication/about/contact_us/ec_ spokespersons/alpha-index_en.htm\#Spokespersons

Comisión Europea. «Strategic Plan 2016-2020. DG Communication». Bruselas: 2016. http://ec.europa.eu/atwork/synthesis/amp/doc/comm_sp_2016-2020_ en.pdf

Comisión Europea. «What is Europe by Satellite?». Acceso el 12 de febrero de 2018. http://ec.europa.eu/avservices/ebs/whatsebs.cfm?sitelang=en

Comisión Europea. Annex to the Commission decision concerning the adoption of the 2014 work programme in the field of Communication, serving as a financing decision. Bruselas: 2013. http://ec.europa.eu/dgs/communication/contracts-andgrants/annual_work_programme/awp/c-2013-8459-work-programme2014-annex_en.pdf

Comisión Europea. Annex to the Commission decision concerning the adoption of the 2015 work programme in the field of Communication, serving as a financing decision. Bruselas: 2014. http://ec.europa.eu/dgs/communication/contracts-andgrants/annual_work_programme/awp/c2014-9492-workprogramme2015-communication-annex_en.pdf 
Comision Europea. Annex to the Commission decision concerning the adoption of the 2016 work programme in the field of Communication, serving as a financing decision. Bruselas: 2015. http://ec.europa.eu/dgs/communication/contracts-andgrants/annual_work_programme/awp/c-2015-9059-work-programme2016-annex_en.pdf

Comisión Europea. Annex to the Commission decision concerning the adoption of the 2017 work programme in the field of Communication, serving as a financing decision. Bruselas: 2016. https://ec.europa.eu/info/sites/info/files/ work-programme2017-annex-dgcomm_december2016_en.pdf

Comisión Europea. Annex to the Commission decision concerning the adoption of the 2018 work programme in the field of Communication, serving as a financing decision. Bruselas: 2017. https://ec.europa.eu/info/sites/info/files/2018-annualwork-programme_annex_to_wp-2018-c2017-8516_dg-comm_en_0.pdf

Comisión Europea. Commission decision concerning the adoption of 2012 work programme in the field of Communication, serving as a financing decision. Bruselas: 2011. http://ec.europa.eu/dgs/communication/contracts-and-grants/ annual_work_programme/awp/progr2012_en.pdf

Comisión Europea. Commission decision of 18.12.2012 concerning the adoption of the 2013 work programme in the field of Communication, serving as a financing decision. Bruselas: 2012. http://ec.europa.eu/dgs/communication/ contracts-and-grants/annual_work_programme/awp/c-2012-9486-decisionworkprogramme2013_en.pdf

Comisión Europea. Communication to the Commission. Action plan to improve communicating Europe by the Commission. Bruselas: 2005. http://ec.europa.eu/ transparency/regdoc/rep/2/2005/EN/2-2005-985-EN-F-0.Pdf

Comisión Europea. Libro blanco sobre una política europea de comunicación. Bruselas: 2006. http://www.larioja.org/empleo-formacion/es/observatorio-empleo/ fondo-social-europeo/comunicacion/comunicacion-igualdad-oportunidades. ficheros/617802-493569_Libro_blanco_politica_europea_comunicacion.pdf

Comisión Europea. Organization chart of the Directorate-General of Communication. Bruselas: 2016. http://ec.europa.eu/dgs/communication/pdf/ organigramme_en.pdf

Comisión Europea. Plan D: democracia, diálogo y debate. Bruselas: 2005. http:// eur-lex.europa.eu/legal-content/ES/TXT/?uri=URISERV\%3Aa30000

Comisión Europea. Report: Communicating Europe to citizens and media. Bruselas: 2012. http://www.europarl.europa.eu/meetdocs/2009_2014/documents/cult/ dv/europetocitizensandmedia/europetocitizensandmediaen.pdf

Consejo de la Unión Europea. 2016 annual activity report of the authorising officer by delegation. Bruselas: Directorate-General Communication and Document Mangement, 2017.

Eur-lex. «Competencias subsidiarias». Acceso el 12 de febrero de 2018. http://eurlex.europa.eu/summary/glossary/subsidiary_powers.html?locale=es.

Euranetplus. «The leading radio network for EU news». Acceso el 12 de febrero de 2018. http://euranetplus-inside.eu/euranetplus-network/

Euronews. «The media. Euronews SA. 26 Shareholders». Acceso el 12 de febrero de 2018. http://www.euronews.com/about 
Europa.eu. «Tu Europa». Acceso el 12 de febrero de 2018. http://europa.eu/ youreurope/citizens/index_es.htm

Europa.eu. «Zona infantil. Juegos y pasatiempos sobre la UE». Acceso el 12 de febrero de 2018. http://europa.eu/kids-corner/index_es.htm

Europa.eu. «Puntos de contacto en su país». Acceso el 12 de febrero de 2018. https://europa.eu/european-union/contact/meet-us_es

García Blanco, Iñaki y Stephen Cushion. «A partial Europe without citizens or eu-level political institutions. How far can Euronews contribute to a European Public Sphere?» Journalism Studies, 11, n. 3 (2010): 393-411. DOI: 10.1080/14616700903378653

Hernández Ruiz, Marta. Políticas y Estrategias de Comunicación de la Comisión Europea. Actores y procesos desde que se aprueban hasta que la información llega a la ciudadanía española. Madrid: CEU Ediciones, 2013. Acceso el 12 de febrero de 2018. http://www.idee.ceu.es/Portals/0/Publicaciones/Docuweb\%20 68\%20UE.pdf

Martínez Nicolás, Manuel. «Agitación en el campo. Nueve ideas para la investigación sobre Comunicación Política en España». Política y Sociedad, 44, n. 2 (2007): 209-227. http://revistas.ucm.es/index.php/POSO/article/view/ POSO0707230209A/22305.

Parlamento Europeo. «Communication policy». Acceso el 12 de febrero de 2018. http://www.europarl.europa.eu/atyourservice/en/displayFtu. html?ftuId=FTU_3.6.8.html

Parlamento Europeo. «Directorate-General for Communication. Bruselas». Acceso el 12 de febrero de 2018. http://www.europarl.europa.eu/the-secretary-general/ en/organisation/directorate-general-for-communication

Parlamento Europeo. Annual Activity Report 2012. DG Communication. Bruselas: 2013. http://www .europarl.europa.eu/document/activities/cont/201309/2013091 1ATT71096/20130911ATT71096EN.pdf

Parlamento Europeo. Annual Activity Report 2013. DG Communication. Bruselas: 2014. http://www.europarl.europa.eu/cmsdata/58960/att_20141113ATT932104417119662789132956.pdf

Parlamento Europeo. Annual Activity Report 2014. DG Communication. Bruselas: 2015. http://www.europarl.europa.eu/cmsdata/87968/COMM_RAA2014_EN_ dec\%20signed.pdf

Parlamento Europeo. Annual Activity Report 2015. DG COMM. Bruselas: 2016. http://www.europarl.europa.eu/cmsdata/104253/5_COMM_RAA2015_EN_ signed.pdf

Parlamento Europeo. Annual Activity Report 2016. DG COMM». Bruselas: 2017. http://www.europarl.europa.eu/cmsdata/125729/5_COMM_RAA2016_ CONSOLIDATED_EN_signed.pdf

Parlamento Europeo. Oficina de Información en España. «La Oficina en España: Quiénes Somos». Acceso el 12 de febrero de 2018. http://www.europarl.es/es/ nuestras_oficinas/oficinas_en_espana/quienes_somos.html

Parlamento Europeo. Oficina de Información en España. «Oficinas en España». Acceso el 12 de febrero de 2018. http://www.europarl.es/es/nuestras_oficinas.html; jsessionid=02C5262899FB7EA7DA645D0BD0BB007D 
Parlamento Europeo. Report on journalism and new media - creating a public sphere in Europe (2010/2015(INI)). Bruselas: 2010. http://www .europarl. europa.eu/sides/getDoc.do?pubRef=-//EP//TEXT+REPORT+A7-20100223+0+DOC+XML+V0//EN

Parlamento Europeo. Research for CULT Committee - Euronews». Bruselas: 2017. http://www.europarl.europa.eu/cmsdata/117126/Euronews_briefing.pdf

Reig, Ramón. Los dueños del periodismo: claves de la estructura mediática mundial y de España. Bacelona: Gedisa, 2011.

Representación de la Comisión Europea en España. «Contacto». Acceso el 12 de febrero de 2018. https://ec.europa.eu/spain/about-us/contact_es

Representación de la Comisión Europea en España. «Quiénes somos». Acceso el 12 de febrero de 2018. https://ec.europa.eu/spain/about-us_es

Seoane Pérez, Francisco. Political communication in Europe. The cultural and structural limits of the European Public Sphere. Reino Unido: Palgrave Macmillan, 2013.

Spence, Alex, y James Panichi. «Tycoon takeover puts Euronews funding in focus». Politico.eu, 25 de agosto de 2015. Acceso el 12 de febrero de 2018. http:// www.politico.eu/article/tycoon-takeover-euronews-funding-meps-commissionegypt-naguib-sawiris/

Voxeurop. «Ayude a sostener Voxeurop». Acceso el 12 de febrero de 2018. http:// www.voxeurop.eu/es

Wallström, Margot. «Comunicando Europa». Elpaís.com. 28 de noviembre de 2008. Acceso el 12 de febrero de 2018. http://elpais.com/diario/2008/11/28/ opinion/1227826805_850215.html

\section{Sobre la autora}

Marta Hernández Ruiz es investigadora en el Instituto de Estudios Europeos de la Universidad CEU San Pablo. Profesora de la materia «Medios de comunicación social en un mundo globalizado» del Máster en Relaciones Internacionales de la misma universidad. Doctora en Estudios Europeos (Mención Cum Laude e Internacional) (2017) y Máster en Relaciones Internacionales (2012) por la Universidad CEU San Pablo. Licenciada en Periodismo por la Universidad de Sevilla (2011).

\section{About the author}

Marta Hernández Ruiz is a researcher at the Institute for European Studies-CEU San Pablo University. Professor of 'The Mass Media and Globalisation' in the Master in International Relations of the same university. $\mathrm{PhD}$ in European Studies (Cum Laude and International Mention) (2017) and Master in International Relations (2012) from the CEU San Pablo University. Graduate in Journalism from the University of Seville (2011). 


\section{Derechos de autor}

Los derechos de autor (para la distribución, comunicación pública, reproducción e inclusión en bases de datos de indexación y repositorios institucionales) de esta publicación (Cuadernos Europeos de Deusto, CED) pertenecen a la editorial Universidad de Deusto. El acceso al contenido digital de cualquier número de Cuadernos Europeos de Deusto es gratuito inmediatamente después de su publicación. Los trabajos podrán leerse, descargarse, copiar y difundir en cualquier medio sin fines comerciales y según lo previsto por la ley; sin la previa autorización de la Editorial (Universidad de Deusto) o el autor. Así mismo, los trabajos editados en CED pueden ser publicados con posterioridad en otros medios o revistas, siempre que el autor indique con claridad y en la primera nota a pie de página que el trabajo se publicó por primera vez en $C E D$, con indicación del número, año, páginas y DOI (si procede). Cualquier otro uso de su contenido en cualquier medio o formato, ahora conocido o desarrollado en el futuro, requiere el permiso previo por escrito del titular de los derechos de autor.

\section{Copyright}

Copyright (for distribution, public communication, reproduction and inclusion in indexation databases and institutional repositories) of this publication (Cuadernos Europeos de Deusto, CED) belongs to the publisher University of Deusto. Access to the digital content of any Issue of Cuadernos Europeos de Deusto is free upon its publication. The content can be read, downloaded, copied, and distributed freely in any medium only for non-commercial purposes and in accordance with any applicable copyright legislation, without prior permission from the copyright holder (University of Deusto) or the author. Thus, the content of $C E D$ can be subsequently published in other media or journals, as long as the author clearly indicates in the first footnote that the work was published in $C E D$ for the first time, indicating the Issue number, year, pages, and DOI (if applicable). Any other use of its content in any medium or format, now known or developed in the future, requires prior written permission of the copyright holder. 